\title{
DESENVOLVIMENTO INICIAL DE DUAS VARIEDADES DE CANA-DE-AÇÚCAR INOCULADAS COM BACTÉRIAS DIAZOTRÓFICAS
}

\author{
Valfredo Almeida Chaves ${ }^{(1)}$, Silvana Gomes dos Santos $^{(1)}$, Nivaldo Schultz ${ }^{(2)}$, Willian \\ Pereira $^{(1)}$, Jailson Silva Sousa ${ }^{(2)}$, Rafael Cassador Monteiro ${ }^{(2)}$ e Veronica Massena Reis ${ }^{(3)^{*}}$ \\ (1) Universidade Federal Rural do Rio de Janeiro, Departamento de Solos, Programa de Pós-Graduação em Agronomia - Ciência do \\ Solo, Seropédica, Rio de Janeiro, Brasil. \\ (2) Universidade Federal Rural do Rio de Janeiro, Departamento de Solos, Seropédica, Rio de Janeiro, Brasil. \\ (3) Empresa Brasileira de Pesquisa Agropecuária, Embrapa Agrobiologia, Seropédica, Rio de Janeiro, Brasil. \\ * Autor correspondente. \\ E-mail: veronica.massena@embrapa.br
}

\section{RESUMO}

A cana-de-açúcar é uma cultura de grande destaque na economia, em razão da produção de açúcar, etanol e energia. Tecnologias que possam contribuir para o aumento da produtividade e qualidade da cultura com mínimos danos ao meio ambiente são necessárias. Objetivou-se avaliar a produção de ácido indol acético de cinco estirpes de bactérias diazotróficas e o efeito da inoculação delas na brotação de duas variedades de cana-de-açúcar, RB867515 e IACSP95-5000. A produção de auxina foi determinada pelo teste colorimétrico, usando o reagente de Salkowski. Para avaliar a germinação, foi conduzido um experimento em casa de vegetação, utilizando-se delineamento experimental em blocos ao acaso com quatro repetições e sete tratamentos: controle não inoculado; inoculação mista com as cinco estirpes e inoculação individual com Gluconacetobacter diazotrophicus $(\mathrm{Gd})$ estirpe BR11281 ${ }^{\mathrm{T}}\left(\mathrm{PAL}-\mathrm{5}^{\mathrm{T}}\right)$, Herbaspirillum seropedicae $(\mathrm{Hs}-\mathrm{BR} 11335=$ HRC54), Herbaspirillum rubrisubalbicans $(\mathrm{Hr}-\mathrm{BR} 11504=\mathrm{HCC103})$, Burkholderia tropica $\left(\mathrm{Bt}-\mathrm{BR}_{11366^{\mathrm{T}}}=\mathrm{PPe} 8^{\mathrm{T}}\right)$ e Azospirillum amazonense (Aa - BR11145 = CBAMc). As bactérias mais eficientes na produção de auxina foram $\mathrm{Hs}$ e $\mathrm{Hr}$, declinando $48 \mathrm{~h}$ após o crescimento. Hr, Aa e Bt aumentaram o índice de velocidade de germinação e o número de brotações nas duas variedades. Na var. RB867515, a velocidade de germinação ainda foi positivamente influenciada pela inoculação mista, sendo o mesmo observado pela inoculação de Gd na var. IACSP95-5000.

Palavras-chave: Saccharum sp., inoculante, promoção de crescimento. 


\title{
ABSTRACT: INITIAL DEVELOPMENT OF TWO SUGARCANE VARIETIES INOCULATED WITH DIAZOTROPHIC BACTERIA
}

\begin{abstract}
Sugarcane is one of the most important crops in the economy due to production of sugar, ethanol, and energy. Technologies are necessary to improve its yield and quality with minimum damage to the environment. We evaluated the indole acetic acid production and germination in the sugarcane varieties RB867515 and IACSP95-5000 after inoculation with five strains of diazotrophic bacteria. The production of indole acetic acid was assayed through the colorimetric method using the Salkowski reagent. To evaluate germination, an experiment was conducted in a greenhouse using a randomized block experimental design with four replications and seven treatments: uninoculated control; mixed inoculation with the five strains; and individual inoculation with Gluconacetobacter diazotrophicus (Gd) estirpe BR11281 $\left(P A L-5^{T}\right)$, Herbaspirillum seropedicae $(H s-B R 11335=$ HRC54), Herbaspirillum rubrisubalbicans $(H r-B R 11504=H C C 103)$, Burkholderia tropica $\left(B t-B R 11366^{T}=P P e 8^{T}\right)$ e Azospirillum amazonense $(A a-B R 11145=C B A M c)$. The most efficient bacteria for production of indol acetic acid were Hs and $\mathrm{Hr}$, and production declined after $48 \mathrm{~h}$ of growth. $\mathrm{Hr}$, Aa, and Bt also improved the germination speed index and number of stalks sprouted in both varieties. Furthermore, in the var. RB867515, germination speed was positively affected by the mixed inoculation, and the same effect was observed from Gd in the var. IACSP95-5000.
\end{abstract}

Keywords: Saccharum sp., inoculum, growth promotion.

\section{INTRODUÇÃO}

A cana-de-açúcar, desde o período colonial, tem se apresentado uma cultura de grande importância para a economia brasileira, ocupando atualmente a terceira posição na balança comercial do agronegócio, principalmente por causa da exportação de açúcar, álcool e energia. O Brasil se destaca no cenário atual como o maior produtor mundial de cana-de-açúcar, onde a área ocupada por essa cultura, no território nacional, passou de 4,8 milhões de hectares em 2000 para 8,8 milhões em 2013 (Conab, 2014).

Produzir mais com menor custo no setor sucroenergético é uma meta a ser seguida em qualquer contexto agrícola. A inoculação com bactérias promotoras de crescimento em cana-de-açúcar pode ser considerada uma alternativa capaz de contribuir para a sustentabilidade desse setor, uma vez que a atuação de mecanismos de promoção de crescimento e o suprimento do $\mathrm{N}$ via fixação biológica de nitrogênio (FBN) permitem ganhos de produtividade e reduzem a utilização de insumos de alto custo, desonerando o sistema de produção da cana-de-açúcar.

A habilidade dessas bactérias em colonizar todo o interior de plantas, localizando-se em nichos protegidos do oxigênio, juntamente com outros fatores, as tornam os mais promissores grupos de diazotróficos associados às plantas não leguminosas, e, como resultado dessa endossimbiose, a planta recebe benefícios ecológicos da presença do simbionte como controle de fitopatógenos ou promoção do crescimento vegetal (Ryan et al., 2008). A interação entre plantas e microrganismos é determinada em parte pelo genótipo da planta, sendo observado que essa serve como abrigo, proporcionando ambiente com umidade favorável e proteção contra dessecação, temperatura e estresse luminoso. A planta também disponibiliza compostos de $\mathrm{C}$ como glicose, frutose e sacarose, que servem como alimento para esses microrganismos (Reis et al., 2000).

A viabilidade da aplicação tecnológica desses microrganismos na cultura da cana-de-açúcar encontra respaldo em muitos trabalhos científicos, que apontam diversos benefícios para essa cultura. Estima-se que a contribuição da FBN para a nutrição nitrogenada da cana-de-açúcar no Brasil pode contribuir com pelo menos $40 \mathrm{~kg} \mathrm{ha}^{-1}$ de N (Urquiaga et al., 2012). Essa variação pode estar relacionada com o genótipo da planta e principalmente com as condições da fertilidade do solo, porém, em se tratando de uma cultura que ocupa milhões de hectares, o suprimento de cerca de $30 \%$ da demanda de N pela FBN certamente trará benefícios ambientais e econômicos para essa cultura.

Além da FBN, a produção de reguladores de crescimento por bactérias diazotróficas também é fator que influencia no crescimento de plantas (Spaepen et al., 2007; Cassán et al., 2014), levando ao maior desenvolvimento do sistema radicular, que torna a absorção de água e nutrientes mais eficiente. A inoculação com bactérias diazotróficas também pode aumentar a velocidade de brotação das gemas e emissão de raízes em colmos de cana-de-açúcar utilizados para o plantio, o que também é desejável especialmente considerando o sistema atual de mudas pré-brotadas (Landell et al., 2012). Em trabalhos realizados em condições de campo, a inoculação mista com bactérias diazotróficas proporcionou aumentos de produtividade de colmos 
e matéria seca total similares ao efeito da adubação com $120 \mathrm{~kg} \mathrm{ha}^{-1}$ de N (Schultz et al., 2012; 2014).

Objetivou-se avaliar a produção de ácido indolacético de cinco estirpes de bactérias diazotróficas e o efeito da inoculação dessas na brotação das variedades de cana-de-açúcar RB867515 e IACSP95-5000.

\section{MATERIAL E MÉTODOS}

Para avaliar a produção de auxinas, cinco estirpes de bactérias diazotróficas, selecionadas previamente por Oliveira et al. (2006) para aplicação como inoculante de cana-de-açúcar, foram utilizadas: Gluconacetobacter diazotrophicus (Gd) estirpe BR $11281^{\mathrm{T}}\left(\mathrm{PAL}-5^{\mathrm{T}}\right)$, Herbaspirillum seropedicae (Hs - BR11335 = HRC54), Herbaspirillum rubrisubalbicans $(\mathrm{Hr}-\mathrm{BR} 11504=\mathrm{HCC} 103)$, Burkholderia tropica $\left(\mathrm{Bt}-\mathrm{BR} 11366^{\mathrm{T}}=\mathrm{PPe} 8^{\mathrm{T}}\right) \mathrm{e}$ Azospirillum amazonense (Aa - BR11145 = CBAMc). A produção de auxinas foi determinada de acordo com método descrito por Sarwar e Kremer (1995), usando o reagente de Salkowski e quantificada a partir de uma curva-padrão construída com concentrações conhecidas de ácido indol acético comercial. O pré-inóculo utilizou colônias isoladas das estirpes bacterianas inoculadas em $20 \mathrm{~mL}$ de meio DYGS com o $\mathrm{pH}$ de crescimento específico para cada bactéria, conforme descrito por Baldani et al. (2014). Para quantificar as auxinas produzidas em meio de cultura, alíquotas de $500 \mu \mathrm{L}$ de solução de cada um dos isolados bacterianos foram colocadas para crescer em $50 \mathrm{~mL}$ de meio DYGS com e sem a adição de L-triptofano $\left(200 \mathrm{mg} \mathrm{L}^{-1}\right)$ e incubadas por $48 \mathrm{~h}$ a $30{ }^{\circ} \mathrm{C}$. Realizaram-se a leitura do crescimento (densidade ótica - D.O. a $600 \mathrm{~nm}$ ) e a quantificação de auxinas às 24 e $48 \mathrm{~h}$. A dosagem de indoles foi feita em $2 \mathrm{~mL}$ de cultivo, que após centrifugação a $10.016 \mathrm{~g}$ por $10 \mathrm{~min}(2 \mathrm{x})$ foi utilizado o sobrenadante; em 1,5 mL desse sobrenadante foi adicionado $1 \mathrm{~mL}$ do reagente de Salkowski. Após a incubação por 30 min no escuro para desenvolvimento de cor, a intensidade da reação foi determinada em espectrofotômetro a $535 \mathrm{~nm}$. A concentração dos compostos indólicos foi estimada com uma curva-padrão, previamente preparada com meio de cultura esterilizado não inoculado, e quantidades conhecidas de ácido indol acético (AIA). A produção final foi medida em $1 \mathrm{~mL}$ e dividida pela unidade de densidade ótica (UDO) para uniformizar pelo crescimento.

Para avaliar o efeito da inoculação na brotação e no acúmulo inicial de biomassa, foi instalado um experimento em casa de vegetação automatizada com controle de umidade e temperatura na Embrapa Agrobiologia, no município de Seropédica, RJ ( $22^{\circ} 44^{\prime} 38^{\prime \prime} \mathrm{S}$ e $43^{\circ} 42^{\prime} 28^{\prime \prime}$ W, 26 m de altitude).
Foram utilizadas duas variedades de canade-açúcar nesse experimento: RB867515, a mais cultivada no Brasil, apresenta maturação média, alto teor de sacarose, alta velocidade de crescimento, crescimento ereto e boa brotação na cana-planta e na soca; e IACSP95-5000, apresenta boa adaptação à colheita mecânica sem queima da palha, maturação média-tardia, alta produtividade, alto teor de sacarose, porte ereto, ótima brotação de soqueiras e ótimo perfilhamento. Minitoletes de tamanho e diâmetro similares contendo uma gema foram retirados do terço superior de colmos das duas variedades com 12 meses de idade.

A inoculação foi realizada com inoculante turfoso contendo as bactérias promotoras de crescimento. Todas as estirpes foram crescidas em meio DYGS por $48 \mathrm{~h}$ a $30^{\circ} \mathrm{C} \mathrm{em}$ mesa agitadora a $175 \mathrm{rpm}$. A população de bactérias presentes no inoculante para implantar esse experimento foi estimada em aproximadamente $10^{8}-10^{9}$ células $\mathrm{mL}^{-1}$. Posteriormente, foram adicionados $75 \mathrm{~mL}$ do inóculo em $175 \mathrm{~g}$ do veículo (turfa moída, neutralizada e esterilizada) embalado em sacos de polietileno. Os sacos plásticos foram mantidos a $30{ }^{\circ} \mathrm{C}$ por sete dias. $\mathrm{O}$ produto final foi composto por cinco pacotes $(250 \mathrm{~g})$ contendo as cinco estirpes individualizadas, que somaram $1,25 \mathrm{~kg}$ de inoculante turfoso. Os tratamentos efetuados foram: controle sem inoculação, inoculação mista com as cinco estirpes e inoculação com cada estirpe aplicada individualmente. $\mathrm{O}$ inoculante foi diluído em água destilada $(1: 100 \mathrm{v} / \mathrm{v})$, padronizando a população das estirpes em $10^{7}$ células $\mathrm{mL}^{-1}$. Os minitoletes inoculados permaneceram imersos por $30 \mathrm{~min}$ na solução inoculante enquanto o tratamento-controle permaneceu imerso em água destilada.

O plantio foi realizado em caixas plásticas de $12 \mathrm{~kg}$ contendo $10 \mathrm{~kg}$ de uma mistura de areia e vermiculita, proporção 1:1 (v/v), previamente esterilizada. As caixas foram distribuídas em blocos ao acaso com sete repetições. Cada repetição foi constituída de oito minitoletes plantados a uma profundidade de $0,04 \mathrm{~m}$ em cada caixa plástica. Os minitoletes plantados nas bordas da caixa (dois de cada lado) foram utilizados para a contagem diária do número de plantas germinadas; e no $14^{\circ}$ dia foram colhidos e secos em estufa a 65 ${ }^{\circ} \mathrm{C}$ para determinar a massa seca de raiz e parte aérea. As repetições centrais (quatro plantas) foram mantidas para determinar o índice de velocidade de germinação conforme descrito por Maguire (1962) e aqui chamado de índice de velocidade de brotação (IVB), em que: IVB = (b1/n + b2/n + b3/n... Bn/n); $\mathrm{B}_{\mathrm{n}}$ é o número de brotações computadas nas "n" contagens; e $\mathrm{N}_{\mathrm{n}}$ é o número de dias do plantio das gemas às " $n$ " contagens. O ensaio finalizou com a estabilização da germinação.

Depois de verificado a validade da análise de variância quanto às pressuposições de normalidade 
(teste de Lilliefors) e homogeneidade de variâncias dos erros (teste de Cochran), as médias das variáveis foram submetidas à análise de variância, recorrendo-se aos testes de Tukey, com $\mathrm{p}<0,01$ ensaio de produção de auxina, e Scott-Knott, com $\mathrm{p}<0,05$ no ensaio em casa de vegetação para comparação entre médias. As análises foram realizadas nos programas estatísticos SAEG $^{\circledR}$ e SISVAR ${ }^{\circledR}$.

\section{RESULTADOS E DISCUSSÃO}

A adição do precursor L-triptofano estimulou a produção de indoles nas cinco estirpes testadas (Figura 1). Na presença desse aminoácido, a produção foi maior na fase exponencial de crescimento $(24 \mathrm{~h})$; a estirpe BR $11281 \mathrm{de}$ $G$. diazotrophicus, que demorou mais a crescer em comparação às demais, produziu mais na segunda avaliação (Figura 1a). Comparando as cinco estirpes/espécies, Hs-BR 11335 produziu 1,7 vez mais indoles que Hr-BR11504 no mesmo período. $\mathrm{Na}$ ausência de triptofano, as cinco estirpes produziram uma média de $6,35 \mu \mathrm{g} \mathrm{mL}{ }^{-1} \mathrm{UDO}^{-1}$, três vezes menos no mesmo período de $24 \mathrm{~h}$, mas a atividade basal difere entre elas (Figura 1b).

$\mathrm{O}$ ácido 3 indole acético (AIA) é a molécula de auxina mais abundante e ativa em sistemas biológicos, sendo produzida por diversos organismos, incluindo as bactérias. Dentre os efeitos associados, destacam-se a iniciação de raízes laterais e adventícias, o estímulo à divisão celular, o alongamento de raízes e colmos (Teale et al., 2006). Em condições de cultivo, a produção de AIA pode variar de 5 a $50 \mu \mathrm{g} \mathrm{mL}^{-1}$, dependendo do meio de cultivo e da estirpe testada (Cassán et al., 2014). Nas condições testadas para este estudo, esses valores foram também observados na presença do precursor L-triptofano. Em Azospirillum brasilense estirpe SM, normalmente o AIA foi produzido em todas as fases de crescimento, mas aumentou significativamente na fase estacionária (Malhotra e Srivastava, 2009), resultado divergente do observado neste estudo. Em $24 \mathrm{~h}$ de crescimento no meio DYGS, $H$. seropedicae atingiu $\mathrm{DO}_{600 \mathrm{~nm}} 0,97$, enquanto $B$. tropica atingiu $\mathrm{DO}_{600 \mathrm{~nm}} 0,54$. Na segunda avaliação $(48 \mathrm{~h}), H$. seropedicae apresentou $\mathrm{DO}_{600 \mathrm{~nm}} 2,49$ e reduziu a produção do AIA; $B$. tropica alcançou 1,7 com redução; e apenas $G$. diazotrophicus chegou a DO 1,12, evidenciando aumento da concentração do AIA. Esses resultados demonstram que as condições testadas promoveram a síntese desses reguladores desde o início do crescimento, o que pode estar relacionado com a estirpe ou com o meio DYGS usado no crescimento, que contém grandes quantidades de diversos aminoácidos pelo uso de extrato de levedura e peptona.

Todas as estirpes de bactérias diazotróficas produziram reguladores de crescimento da classe dos indoles, o que modificou o índice de velocidade de brotação nas duas variedades de cana testadas (Figura 2). Comparando as duas variedades, notase que a resposta difere entre elas quando as cinco estirpes são aplicadas em mistura. $\mathrm{Na}$ variedade responsiva à inoculação, $\mathrm{RB} 867515$, a mistura

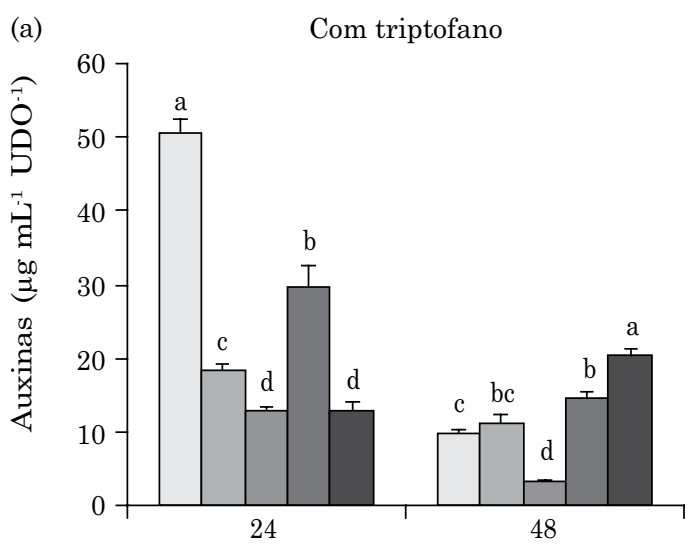

(b)

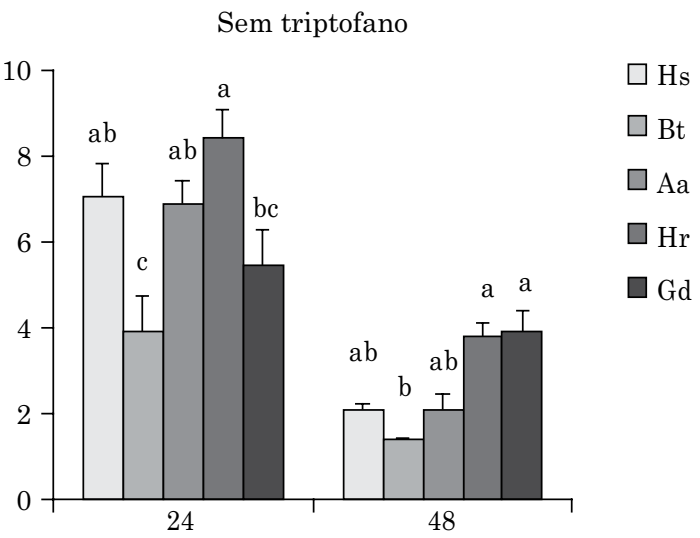

Tempo (h)

Figura 1. Produção de indoles de cinco estirpes de bactérias diazotróficas na presença (a) e ausência (b) do precursor L-triptofano. Valores médios de três repetições e barras representam o desvio-padrão. Médias seguidas de diferentes letras minúsculas diferem entre si pelo teste Tukey a 1 \%. Gd: Gluconacetobacter diazotrophicus estirpe BR11281 ${ }^{\mathrm{T}}\left(\mathrm{PAL}-5^{\mathrm{T}}\right)$, Hs: Herbaspirillum seropedicae $(\mathrm{Hs}-\mathrm{BR} 11335=\mathrm{HRC54})$, Hr: Herbaspirillum rubrisubalbicans (Hr - BR11504 = HCC103), Bt: Burkholderia tropica $\left(\mathrm{Bt}-\mathrm{BR}_{11366^{\mathrm{T}}}=\mathrm{PPe} 8^{\mathrm{T}}\right)$ e Aa: Azospirillum amazonense $(\mathrm{Aa}-\mathrm{BR} 11145=\mathrm{CBAMc})$. 
diferiu do controle (Figura 2a), não sendo o mesmo observado na var. não responsiva - IACSP95-5000, selecionada para solos mais ricos, onde a mistura não diferiu do controle (Figura $2 \mathrm{~b}$ ). Na aplicação individual, $\mathrm{Hr}$ evidenciou os melhores índices nas duas variedades, seguido de Aa-BR11145 e Bt-BR11366 ${ }^{\mathrm{T}}$. A superioridade de germinação na maioria dos casos apresentou correlação com os dados de produção de AIA in vitro. O índice de germinação referente à inoculação com Gd-BR $11281^{\mathrm{T}}$ foi igual ao controle não inoculado, evidenciando que a quantidade de indoles não foi suficiente para estimular a brotação; o inverso ocorreu com a inoculação individual de Hs-BR11335, onde houve elevada produção de AIA.

Auxinas aplicadas às raízes possuem um ótimo de resposta na concentração ao redor de $10^{-8}-10^{-9} \mu \mathrm{mol} \mathrm{L}^{-1}$ e se correlacionam com o maior número de células das bactérias que as produzem em elevadas concentrações como o Azospirillum brasilense (Spaepen et al., 2007). Nas duas variedades testadas, Hs-BR 11335 , que mais produziu AIA, não diferiu do controle e não estimulou o crescimento das plantas. O inverso ocorreu com Bt-BR11366, que produziu 2,8 vezes menos indoles do que $H$. seropedicae in vitro e dobrou a velocidade de germinação nas duas variedades. De modo geral, a inoculação individual com Hr-BR11504, Aa-BR11145 e Bt-BR $11366^{\mathrm{T}}$ proporcionou velocidade de brotação significativamente superior ao controle nas duas variedades, sendo o mesmo observado para a inoculação mista na var. RB867515 e a inoculação com Gd-BR 11281 ${ }^{\mathrm{T}}$ na var. IACSP95-5000. O número de brotações diferiu entre as variedades e foi estimulado por distintos tratamentos de inoculação (Figuras 3a e 3b). Somente a variedade RB867515 brotou todos os toletes de cada caixa e com a inoculação mista e de Hr-BR11504 (Figura 3a), seguido de Aa-BR11145 e Bt-BR11366 ${ }^{\mathrm{T}}$. Na variedade IACSP95-5000, a inoculação de Hr-BR 11504, Aa-BR11145 e Bt-BR $11366^{\mathrm{T}}$ confirmaram os resultados da velocidade de brotação e essas três estirpes foram benéficas nos dois genótipos de cana-de-açúcar testados (Figura 3b).

Resultados promissores com a inoculação de uma única espécie diazotrófica já foram observados por Suman et al. (2005). Esses autores inocularam isolados de $G$. diazotrophicus na variedade de cana-de-açúcar CoSe92423 cultivada na Índia e também obtiveram aumentos significativos da porcentagem de germinação para essa variedade. Para as variedades RB867515 e IACSP95-5000, tomando-se como exemplo a estirpe Hr-BR11504, percebeu-se que a velocidade de brotação do tratamento inoculado foi $55 \%$ superior ao controle na var. RB867515 e $154 \%$ na var. IACSP95-5000. Como o plantio de cana-de-açúcar atualmente preconiza a utilização de mudas pré-brotadas denominada de MPB (Landell et al., 2012), essa modificação na velocidade de obtenção de mudas é desejável, e uma única estirpe foi capaz de acelerar esse processo independentemente do genótipo da planta, quando comparada às outras estirpes, o que é desejável para se recomendar novo processo biotecnológico ao setor. Tendo em vista que a interação entre plantas e microrganismos é determinada em parte pelo genótipo da planta (Oliveira et al., 2006), é provável que diferenças (a)

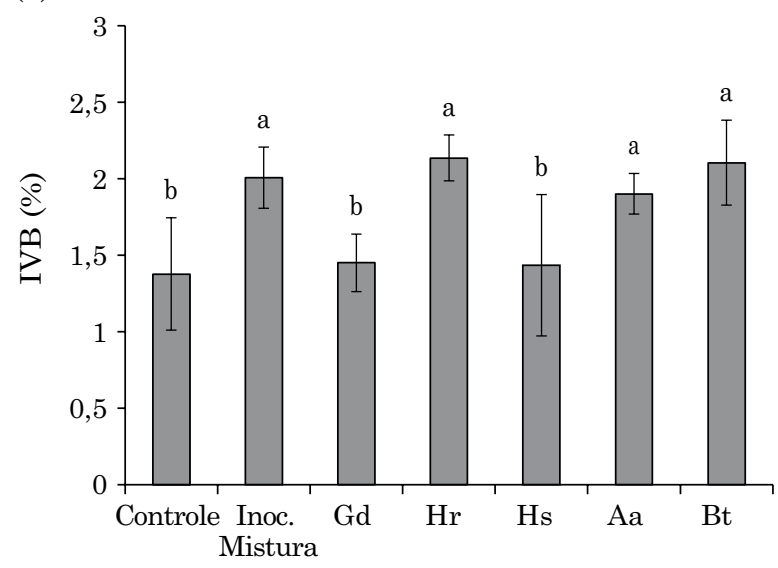

(b)

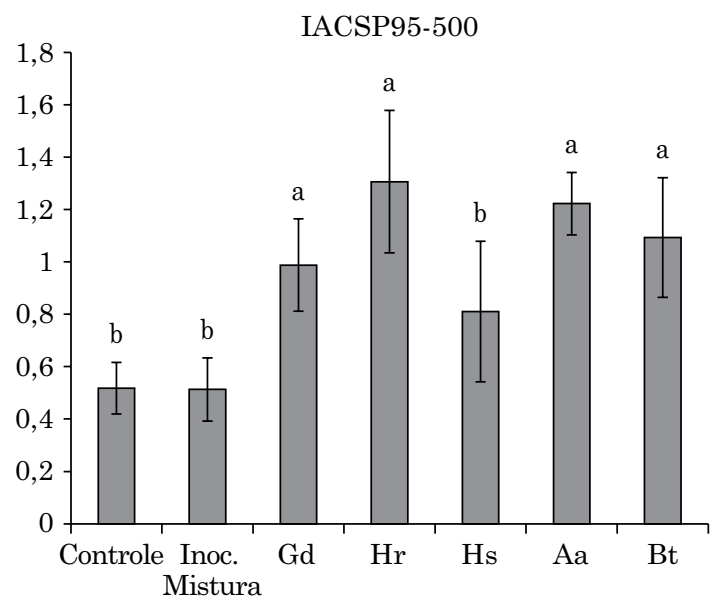

Figura 2. Índice de velocidade de brotação (IVB). (a) variedade RB867515; e (b) variedade IACSP95-5000. Médias seguidas de diferentes letras minúsculas diferem entre si pelo teste Scott-Knott a $5 \%$. CV: (a) 26,45 \%; e (b) 40,2 \%. Gd: Gluconacetobacter diazotrophicus estirpe BR11281 ${ }^{\mathrm{T}}$ (PAL-5 $^{\mathrm{T}}$ ), Hs: Herbaspirillum seropedicae (Hs - BR11335 = HRC54), Hr: Herbaspirillum rubrisubalbicans

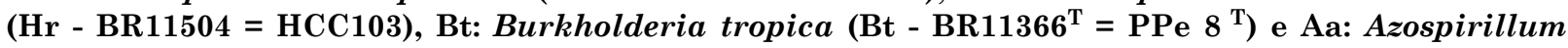
amazonense (Aa - BR11145 = CBAMc). 
(a)

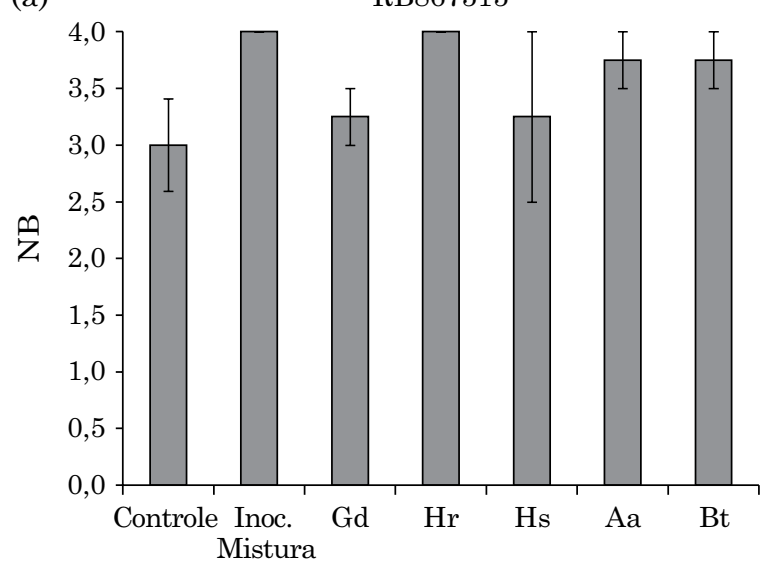

(b)

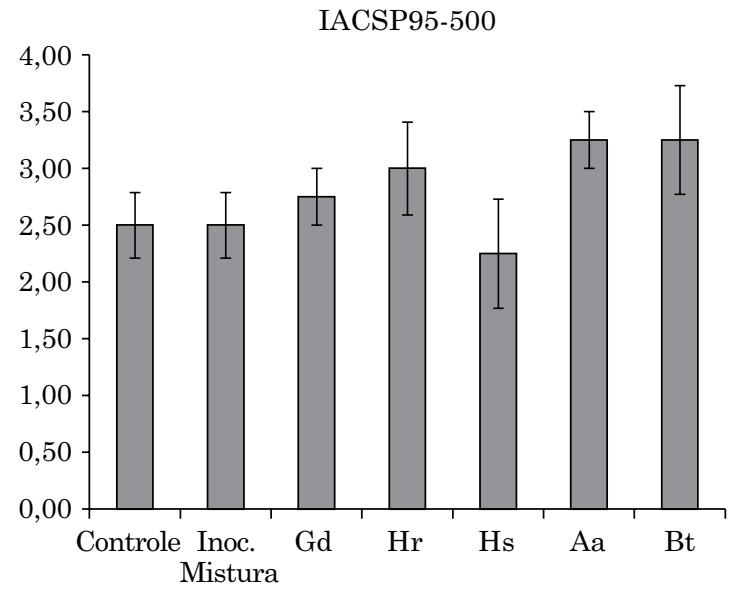

Figura 3. Número de brotações no $20^{\circ}$ dia após o plantio (NB). (a) variedade RB867515; e (b) variedade IACSP95-5000. Médias seguidas de diferentes letras minúsculas diferem entre si pelo teste Scott-Knott a 5 \%. CV: (a) 20,11\%; e (b) 24,77\%. Gd: Gluconacetobacter diazotrophicus estirpe BR11281 ${ }^{\mathrm{T}}\left(\mathrm{PAL}-5^{\mathrm{T}}\right)$, Hs: Herbaspirillum seropedicae (Hs - BR11335 = HRC54), Hr: Herbaspirillum rubrisubalbicans $(\mathrm{Hr}-\mathrm{BR} 11504=\mathrm{HCC103})$, Bt: Burkholderia tropica $\left(\mathrm{Bt}-\mathrm{BR}_{1366^{\mathrm{T}}}=\mathrm{PPe} 8^{\mathrm{T}}\right)$ e Aa: Azospirillum amazonense (Aa - BR11145 = CBAMc).

genéticas entre as variedades tenham modificado a resposta das plantas para esses tratamentos, uma vez que a inoculação e o cultivo dessas deram-se em condições idênticas. Em experimento de campo para a avaliação do inoculante misto na produtividade de colmos e matéria seca total, Schultz et al. $(2012 ; 2014)$ verificaram respostas diferenciadas para as variedades RB867515 e RB72454 sob condições idênticas de tratamentos, reforçando a hipótese de que o genótipo, associado às condições climáticas, influencia a resposta da cultura à aplicação do inoculante.

O acúmulo de biomassa durante 14 dias de ensaio evidenciou que a variedade RB867515 mantém uma proporção de massa seca de parte aérea e raiz equilibrada, enquanto a variedade IACSP95-5000 emite mais raízes (Figura 4). Observando-se a relação raiz/parte aérea, percebeu-se que as duas variedades têm comportamentos diferentes durante a fase de germinação, em que a variedade IACSP95-5000 prioriza o desenvolvimento radicular; e a $\mathrm{RB} 867515$, o desenvolvimento da parte aérea (Figuras 4a e 4b).

$\mathrm{Na}$ variedade IACSP95-5000 (Figura 4b), a produção de matéria seca de parte aérea foi significativamente superior em resposta à inoculação mista e inoculação individual de Gd-BR11281 T , Hr-BR11504 e Hs-BR 11335. Portanto, cabe destacar que, embora as estirpes $A$. amazonense e B. tropica tenham aumentado significativamente a velocidade de brotação nas duas variedades, a produção de massa seca de parte aérea obtida nesses tratamentos para as duas variedades foi estatisticamente igual ao controle na avaliação realizada no $14^{\circ}$ dia após o plantio. A relação raiz/parte aérea para a variedade IACSP95-5000 foi significativamente superior no tratamento-controle e na inoculação com Aa-BR11145, em razão à produção de biomassa de parte aérea significativamente inferior nesses tratamentos.

Nos toletes de cana-de-açúcar, os órgãos da gema e dos primórdios radiculares passam do estado latente para o estado ativo de crescimento e desenvolvimento por causa das mudanças das reservas nutritivas pela atividade de enzimas e reguladores de crescimento (Casagrande e Vasconcelos, 2010). Uma vez que a brotação das gemas e emissão de raízes na cana é dependente da atuação de reguladores de crescimento, o fato de os minitoletes utilizados nesse experimento terem sido inoculados com bactérias amplamente reconhecidas como produtoras de reguladores de crescimento (Bastián et al., 1998; El-Sayed et al., 2002) explica as diferenças no crescimento das plantas entre os tratamentos, em razão da contribuição hormonal desses microrganismos, pois a produção de auxinas, citocininas, giberelinas e etileno por bactérias associadas aos vegetais é considerada agentes causais da alteração do crescimento e da transformação vegetal (Cassán et al., 2014). Efeitos no desenvolvimento inicial de plantas de cana-de-açúcar também têm sido observados por outros autores, em virtude da ação de microrganismos promotores de crescimento, substâncias húmicas e reguladores de crescimento sintéticos (Marques Júnior et al., 2008; Serna-Cock et al., 2011). 
(a)

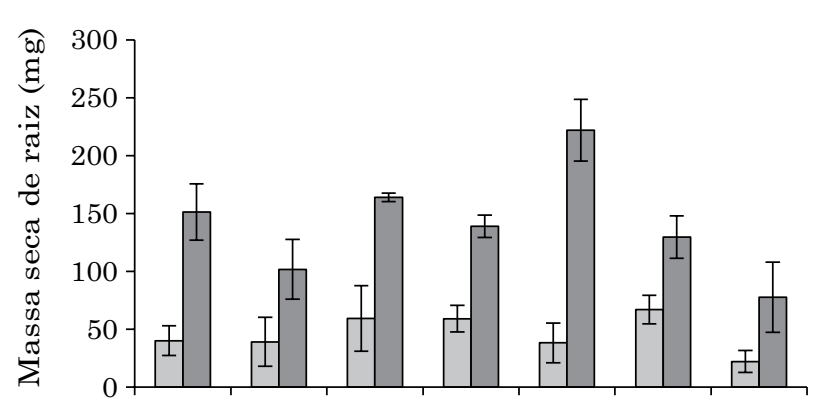

(c)

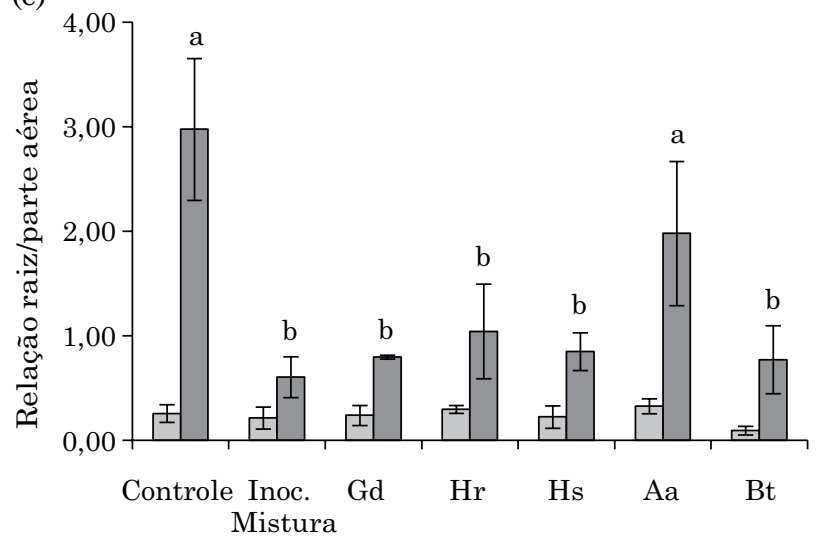

(b)

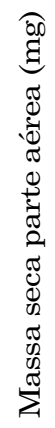

$\square \mathrm{RB} 867515 \quad \square \mathrm{IACSP95-500}$

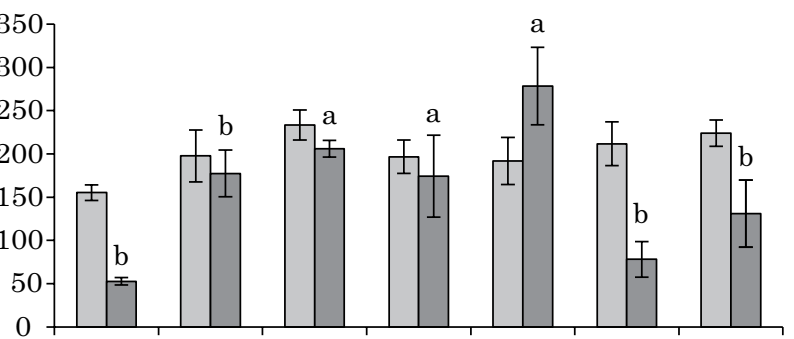

(d)

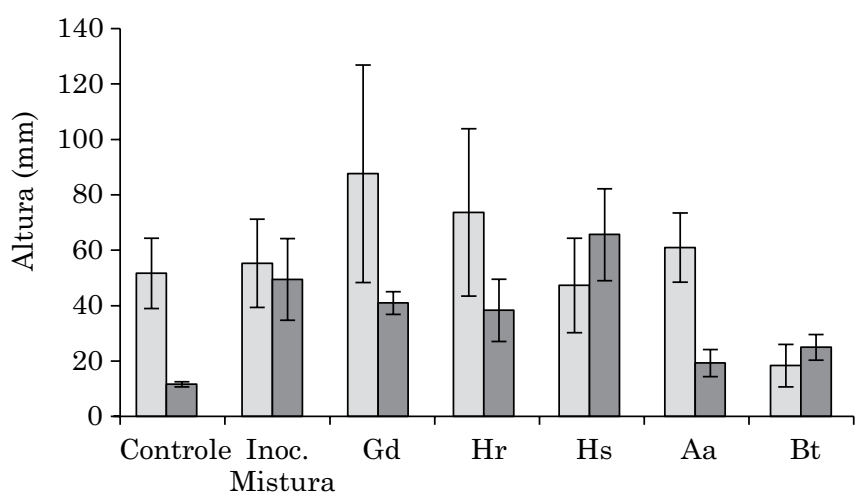

Figura 4. Acúmulo de biomassa de plantas de cana-de-açúcar inoculadas com bactérias diazotróficas no $14^{\circ}$ dia após o plantio. (a) Matéria seca de raízes; (b) Matéria seca de parte aérea; (c) Relação raiz/parte aérea; e (d) Altura de parte aérea. Médias seguidas de diferentes letras minúsculas diferem entre si pelo teste Scott-Knott a $5 \%$. Coeficientes de variação (\%) para a var. RB867515: (a) 65,83; (b) 19,72; (c) 62,92; e (d) 38,69; e para a var. IACSP95-000: (a) 27,56; (b) 31,11; (c) 59,69; e (d) 46,42. Gd: Gluconacetobacter diazotrophicus estirpe BR11281 ${ }^{\mathrm{T}}\left(\mathrm{PAL}^{\mathrm{T}} \mathrm{S}^{\mathrm{T}}\right.$ ), Hs: Herbaspirillum seropedicae (Hs - BR11335 = HRC54), Hr: Herbaspirillum rubrisubalbicans $(\mathrm{Hr}-\mathrm{BR} 11504=\mathrm{HCC103})$, Bt: Burkholderia tropica $\left(\mathrm{Bt}-\mathrm{BR}_{11366}^{\mathrm{T}}=\mathrm{PPe} 8^{\mathrm{T}}\right)$ e Aa: Azospirillum amazonense (Aa - BR11145 = CBAMc).

\section{CONCLUSÕES}

As bactérias que apresentam maior produção de compostos indólicos são Herbaspirillum seropedicae (BR11335) e Herbaspirillum rubrisubalbicans (BR11504).

A diferença do genótipo influencia na resposta da cana-de-açúcar à inoculação.

A inoculação individual de Herbaspirillum rubrisubalbicans (BR11504), Azospirillum amazonense (BR11145) e Burkholderia tropica (BR11366) aumenta o índice de velocidade de brotação nas duas variedades testadas.

A inoculação mista e a individual de Gluconacetobacter diazotrophicus (BR11281), Herbaspirillum rubrisubalbicans (BR11504) e Herbaspirillum seropedicae (BR11335) promovem aumento da massa seca da parte aérea na var. IACSP95-5000.

\section{AGRADECIMENTOS}

À Coordenação de Aperfeiçoamento de Pessoal de Nível Superior (CAPES), ao Conselho Nacional de Desenvolvimento Científico e Tecnológico (CNPq) e à Fundação Carlos Chagas de Amparo à Pesquisa do Estado do Rio de Janeiro (FAPERJ), pelas bolsas concedidas. À Embrapa Agrobiologia projeto número 03.13.00.016.

\section{REFERÊNCIAS}

Baldani JI, Reis VM, Videira SS, Boddey LH, Baldani VLD. The art of isolating nitrogen-fixing bacteria from non-leguminous plants using $\mathrm{N}$-free semi-solid media: a practical guide for microbiologists. Plant Soil. 2014;384:413-31. 
Bastián F, Cohen A, Piccoli P, Luna V, Baraldi R, Bottini R. Production of indole-3-acetic acid and gibberellins A1 e A3 by Acetobacter diazotrophicus and Herbaspirillum seropedicae in chemically-defined culture media. Plant Growth Regul. 1998;24:7-11.

Casagrande AA, Vasconcelos ACM. Fisiologia da parte aérea In: Dinardo-Miranda LL, Vasconcelos ACM, Landell MGA, editores. Cana-de-açúcar. Campinas: Instituto Agronômico; 2010. p.57-78.

Cassán F, Vanderleyden J, Spaepen S. Physiological and agronomical aspects of phytohormone production by model plantbacteria-promoting rhizobacteria (PGPR) belonging to the genus Azospirillum. J Plant Growth Regul. 2014;33:440-59.

Companhia Nacional de Abastecimento - Conab. Acompanhamento da safra brasileira: cana-de-açúcar, segundo levantamento, agosto/2013. [Acessado em: 3 mar. 2015]. Disponível em: http://www.conab.gov.br/

El-Sayed T, Radwan ED, Mohamed ZK, Reis V M. Production of indole-3-acetic acid by different strains of Azospirillum and Herbaspirillum spp. Symbiosis. 2002;32:39-54.

Landell MGA, Campana MP, Figueiredo P, Xavier MA, Anjos IA, Dinardo-Miranda LL, Scarpari MS, Garcia JC, Bidóia MAP, Silva DN, Mendonça JR, Kanthack RAD, Campos MF, Brancalião SR, Petri RH, Miguel PEM. Sistema de multiplicação de cana-de-açúcar com uso de mudas pré-brotadas (MPB), oriundas de gemas individualizadas. Campinas: Instituto Agronômico; 2012. (Documentos, 109).

Maguire JD. Speed of germination aid in selection and evaluation for seedling emergence and vigor. Crop Sci. 1962;2:176-7.

Malhotra M, Srivastava S. Stress-responsive indole-3-acetic acid biosynthesis by Azospirillum brasilense SM and its ability to modulate plant growth. Eur J Soil Biol. 2009;45:73-80.

Marques Júnior RB, Canellas LP, Silva LG, Olivares FL. Promoção de enraizamento de microtoletes de cana-de-açúcar pelo uso conjunto de substâncias húmicas e bactérias diazotróficas endofíticas. R Bras Ci Solo. 2008;32:1121-8.

Oliveira ALM, Canuto EL, Urquiaga S, Reis VM, Baldani JI. Yield of micropropagated sugarcane varieties in different soil types following inoculation with diazotrophic bacteria. Plant Soil. 2006;284:23-32.
Reis VM, Baldani JI, Baldani VLD, Döbereiner J. Biological nitrogen fixation in gramineae and palm trees. Crit Rev Plant Sci. 2000;19:227-47.

Ryan RP, Germaine K, Franks A, Ryan DJ, Dowling DN. Bacterial endophytes: recent developments and applications. FEMS Microbiol Lett. 2008;23:1-9.

Sarwar M, Kremer RJ. Determination of bacterially derived auxins using a microplate method. Lett Appl Microbiol. $1995 ; 20: 282-5$.

Schultz N, Morais RF, Silva JA, Baptista RB, Oliveira RP, Leite JM, Pereira W, Carneiro Júnior JB, Alves BJR, Baldani JI, Boddey RM, Urquiaga S, Reis VM. Avaliação agronômica de duas variedades de cana-de-açúcar inoculadas com bactérias diazotróficas e adubadas com nitrogênio. Pesq Agropec Bras. 2012;47:261-8.

Schultz N, Silva JA, Sousa JS, Monteiro RC, Oliveira RP, Chaves VA, Pereira W, Silva MF, Reis VM, Urquiaga S. Inoculation of sugarcane with diazotrophic bacteria. R Bras Ci Solo. 2014;38:359-71.

Serna-Cock L, Arias-García C, Hernandez LJV. Effect of biofertilization on the growth of potted sugarcane plants (Saccharum officinarum). Biotecnol Sector Agropec Agroind. 2011;9:85-95.

Spaepen S, Vanderleyden J, Remans R. Indole-3-acetic acid in microbial and microorganism-plant signaling. FEMS Microbiol Rev. 2007;31:425-48.

Suman A, Gaur A, Shrivastava AK, Yadav RL. Improving sugarcane growth and nutrient uptake by inoculating Gluconacetobacter diazotrophicus. Plant Growth Regul. 2005;47:155-62.

Teale W, Paponov I, Palme K. Auxin in action: signalling, transport and the control of plant growth and development. Nat Rev Molec Cell Biol. 2006; 7:847-59.

Urquiaga S, Xavier R, Morais RF, Batista R, Schultz N, Leite JM, Resende A, Alves BJR, Boddey RM. Evidence from field nitrogen balance and ${ }^{15} \mathrm{~N}$ natural abundance data of the contribution of biological $\mathrm{N}_{2}$ fixation to Brazilian sugarcane varieties. Plant Soil. 2012;356:5-21. 